DOI

http://dx.doi.org/10.1590/2236-463320151005

"At the point that the public needs require": Political Experience and Changes in Temporality in Brazilian Political debate of the 1830s

\section{"Ao ponto que as necessidades públicas exigem": experiência política e reconfiguração do tempo no debate político brasileiro da década de 1830}

Luisa Rauter Pereira ${ }^{1}$

Universidade Federal de Ouro Preto,

Ouro Preto - MG, Brasil

e-mail: lurauterp@gmail.com

\section{Resumo}

0 artigo analisa momentos centrais do debate parlamentar da década de 1830 no Brasil, sob a ótica da Teoria da História e da História da Historiografia, buscando compreender a política institucional como local de reconfiguração da experiência temporal. Pretendemos demonstrar que a década de 1830, com seus conflitos políticos e sociais de grande intensidade, foi um momento de grandes mudanças neste âmbito, com a ascensão de um discurso conservador que valorizou os fatos, experiências e circunstâncias como elementos fundamentais para a projeção da ação política.

\section{Abstract \\ The article examines key moments of the parliamentary debate of the 1830s in Brazil from the perspective of Theory of History and History of Historiography, trying to understand the institutional policy as a place of profound transformation in temporal experience. We intend to demonstrate that the 1830s, with its political and social conflicts of high intensity, was a time of great change in this area, with the rise of a conservative discourse which valued the facts, experiences and circumstances as fundamental elements for the projection of political action.}

Palavras-chaves

temporalidade, História do Brasil Imperial, História Política do Brasil

Keywords

temporality, History of Imperial Brazil, Political History of Brazil
Doutora em Ciências Humanas, Ciência Política e professora no Departamento de História da Universidade Federal de Ouro Preto (ICHS - UFOP I Ouro Preto-MG - Brasil). Apoio: Fundação de Amparo à Pesquisa de Minas Gerais (FAPEMIG), PRONEM - Variedades do Discurso Histórico. 
Gostaria de agradecer o apoio como assistente de pesquisa de Larissa Breder Teixeira, aluna do Curso de História da Universidade Federal de Ouro Preto e bolsista de Iniciação Científica do projeto de pesquisa financiado pela Fundação de Amparo à Pesquisa de Minas Gerais, sob minha orientação.

3

PALONEN, Kari. Tempos da política e

temporalização conceitual: um novo paradigma da história Conceitual. In: FERES JUNIOR, João; JASMIN, Marcelo (orgs). História dos Conceitos: Diálogos Transatlânticos. Rio de Janeiro: Ed. PUCRio : Ed Loyola : IUPERJ, 2007. p.31-44.

4

ARAUJO, Valdei. A experiência do tempo. Conceitos e narrativas na formação nacional brasileira (1813-1845). São Paulo: Hucitec, 2008.

5

PALTI, Elias J. El tiempo de La política. El siglo XIX reconsiderado. Buenos Aires: Siglo Veinteuno Editores, 2007.

6

0 projeto resultou em importantes produtos reunidos nos dois tomos já publicados do Diccionario Político y Social Del Mundo Iberoamericano organizado por Javier Fernandez Sebastián, professor catedrático em História do Pensamento Político da Universidade do País Basco.

7

Vários trabalhos de jovens pesquisadores tem se dedicado a investigar a relação entre temporalidade, historicidade e política. Em especial, podemos citar as seguintes dissertações de mestrado: 1) SANTOS, Cristiane Alves Camacho dos. Escrevendo a história do futuro: a leitura do passado no processo de independência do Brasil. 2010. 145f. Dissertação (Mestrado em História Social). Faculdade de Filosofia, Letras e Ciências Humanas, Universidade de São Paulo, São Paulo, 2010; 2) RODRIGUES, Thamara de Oliveira. $A$ independência de Portugal. História, progresso e decadência na obra de Francisco Solano Constâncio (1808-1840). 2014. 148f. Dissertação (Mestrado em História) Instituto de Ciências Humanas e Sociais, Universidade Federal de Ouro Preto, Ouro Preto, 2014; 3) FANNI, Rafael. Temporalização dos discursos políticos no processo de Independência do Brasil ( 1820-1822 ). 2014. 230f. Dissertação (Mestrado em História Social) Faculdade de Filosofia, Letras e Ciências Humanas, Universidade de São Paulo, São Paulo, 2014.

8

Ver: SOUZA, lara Lis Franco Schiavinatto Carvalho. Pátria Coroada. 0 Brasil como Corpo Político Autônomo (1780-1831). São Paulo: Fundação Editora da UNESP, 1999.

9

SOUZA, lara Lis Franco Schiavinatto Carvalho. Loc. Cit.

10

No tratado de 1826, o Brasil se comprometeu a abolir o comércio de escravos no Atlântico. Outro tratado estipulou que a partir de 1831 todo traficante brasileiro aprisionado pela marinha britânica seria julgado por uma comissão formada por britânicos, brasileiros e franceses em Serra Leoa. Ver: ALVES, Andréa Firmino. A Escravidão no
Neste artigo ${ }^{2}$, analisaremos alguns aspectos do debate político brasileiro dos anos de 1830 no Senado e Câmara dos Deputados, procurando mostrar como a experiência política daqueles anos foi fundamental na transformação da forma como o tempo foi interpretado e vivido pelas lideranças que compunham a representação na Corte do Rio de Janeiro naquele momento. Nossa proposta é entender as linguagens e conceitos políticos em uso no espaço público e nas instituições representativas como local importante para se perceber as formas de consciência e orientação temporal das épocas e sociedades. Neste sentido, seguimos os passos abertos por autores já clássicos como Reinhart Koselleck, Quentin Skinner e John Pocock, e também por autores como Kari Palomnen ${ }^{3}$, Valdei Lopes Araujo ${ }^{4}$, Elias J. Palti ${ }^{5}$, além dos trabalhos desenvolvidos há quase uma década pelas dezenas de investigadores envolvidos no projeto lberconceptos ${ }^{6}$. A proposta deste artigo se insere, portanto, nesta importante linhagem de estudos que vem repercutindo também em uma série de recentes trabalhos. ${ }^{7}$

Na primeira década do Brasil como país independente, o acirramento da disputa política levou à Abdicação do primeiro Imperador, em 7 de Abril de $1831 .{ }^{8} \mathrm{~A}$ crescente onda de motins e guerras civis se espalhou pelas províncias do Império, em meio a um período marcado pelas incertezas de um governo provisório, o que constituiu uma experiência estruturante da consciência política das elites dirigentes do novo país. Tais experiências e suas interpretações foram ao mesmo tempo reorientações no tempo histórico de grande abrangência, hipótese que iremos esboçar nas próximas páginas.

0 conjunto de insatisfações que levou à abdicação do Imperador era bastante heterogêneo. Por um lado, havia na Corte do Rio de Janeiro uma massa populacional formada em sua maioria por libertos, mestiços e escravos urbanos, e que vivia em acentuada pobreza notadamente na segunda metade dos anos 1820, quando houve um forte aumento nos preços. ${ }^{9} \mathrm{~A}$ violência urbana era grande. Revoltas e motins urbanos eram frequentes, assim como brigas entre brasileiros e portugueses. Nos jornais de tendência liberal, o governo e a própria pessoa de D. Pedro I passaram a ser cada vez mais criticados, especialmente após a veiculação das ligações do Imperador com a elite portuguesa residente no país e sua interferência no processo sucessório português.

A elite brasileira e liberal passou a agredir o governo de D. Pedro I especialmente a partir da segunda metade da década de 1820. A assinatura de tratados antitráfico com a Grã-Bretanha causara desconfiança com relação ao Imperador, que sabidamente era a favor da extinção gradual da atividade. ${ }^{10}$ Essa elite política escravista dominante na câmara dos deputados bradava por "liberdade" contra a "tirania" do Imperador, numa defesa da Constituição de 1824 e dos poderes da assembleia. " Havia também um grupo republicano minoritário, mas que vinha se solidificando desde a Independência, ${ }^{12}$ adepto de um liberalismo exaltado revolucionário, e que liderava a maior parte dos motins urbanos, radicalizando a crítica aos portugueses, ao sistema político e ao Imperador. ${ }^{13}$

Este movimento difuso desembocou na Abdicação de abril de 1831, dando ensejo à tomada da direção do Estado pelo grupo liberal moderado, num governo regencial que deveria ter fim com a maioridade do herdeiro do trono que, na época, era uma criança. Logo após a tomada do poder, foram postos em debate projetos de descentralização político-administrativa, o que pôs em questão o desenho centralizador e marcadamente monárquico do Primeiro Reinado. 
Império do Brasil. Revista Múltipla, Brasília, n.10 (20), p.33-50, julho/2006.

11

LENHARO, Alcir. As tropas da Moderação. 0 Abastecimento da Corte na formação política do Brasil. 1808-1842. São Paulo: Símbolo, 1979. Lenharo revela como muitos dos comerciantes e produtores de Minas, São Paulo e interior do Rio de Janeiro, do ramo de abastecimento da Corte, transferiram as sedes de suas empresas e moradias para a corte carioca. Mantinham representantes de seus interesses na Assembleia, como Bernardo Pereira de Vasconcelos e outros. Para este autor, o liberalismo moderado defendido por este grupo se explica em grande parte pela prioridade de que se revestia a questão da manutenção da ordem e da escravidão, essenciais para a manutenção e expansão de seus negócios. 12

Ver LEITE, Renato Lopes. Republicanos e Libertários. Pensadores radicais no Rio de Janeiro (1822). Rio de Janeiro: Civilização Brasileira, 2000 13

BASILE, Marcello Otávio Néri de Campos. Anarquistas, rusguentos e demagogos: os liberais exaltados e a formação da esfera publica na corte imperial (1829-1834). 2000. 420f. Dissertação (Mestrado em História). Instituto de Filosofia e Ciências Sociais, Universidade Federal do Rio de Janeiro, Rio de Janeiro, 2000. p.333.

14

Capítulo que fará parte de um livro organizado por Helena Mollo que reunirá as contribuições do I Colóquio PRONEM - Variedades do Discurso Histórico, a ser publicado em 2015.

15

ARAÚJO, Valdei. Op. Cit.
16

ANAIS DO SENADO IMPERIAL, 23 de maio de 1832, p.115. Disponivel em: <http://www.senado. leg.br/publicacoes/anais/asp/IP_Anaislmperio.asp $>$.
Desde o início do debate do projeto no Senado e na Câmara já eram revelados os impasses e limites com que tal plano liberalizante deveria defrontar-se. Os problemas da forma da representação e dos limites da liberdade no novo país de dimensão continental apareceriam de forma contundente. Acredito que tais experiências políticas foram centrais na reformulação das percepções do tempo no espaço público. Tratou-se de um momento especial, em que diversos anseios foram expostos, uma vez que a disputa política foi adensada pelo relativo vazio de poder ocasionado pela queda do Imperador. Na medida em que conflitos entre as elites locais e 0 poder central, e revoltas populares de todo tipo se avolumaram na capital e nas províncias, a questão das possiveis formas e limites da representação política se tornou candente. A interpretação sobre tais experiências ordenou e fortaleceu as bases da linguagem política que sustentou do ponto de vista simbólico o Império até, pelo menos, os anos 1860.

Como já analisei em outro lugar ${ }^{14}$, a linguagem da racionalidade e das virtudes dos anos de 1820, que se orientava para a busca de princípios políticos universais e eternos ${ }^{15}$ que pudessem guiar a construção do novo país, em que o exemplo histórico greco-romano, por exemplo, era ainda especialmente presente, se transformaria rapidamente nos anos 1830. Nestas décadas, em que a experiência política do país independente já começava a tomar maior densidade, a linguagem dos princípios abstratos expressos, entre outras coisas, na história exemplar, cada vez mais deixaria de satisfazer as exigências do momento.

A discussão sobre o projeto de reforma constitucional - que daria origem ao chamado Ato Adicional - pôs em cena um tipo majoritário de argumentação, que, em variados graus, esteve presente na linguagem politica da década, prolongando-se pelas décadas seguintes. Para compreendê -la, vejamos o que disse o senador pela província do Ceará, José Martiniano de Alencar, durante os momentos iniciais do debate. 0 senador argumentou em favor de reformas, já que as nações mais "felizes na sua marcha política" não são aquelas que realizam mudanças abruptas e repentinas, mas aquelas que "vão paulatinamente ampliando suas instituições ao ponto que as necessidades públicas exigem", sendo a Inglaterra o maior exemplo desta virtude. 0 projeto em questão era, para o Senador,

\footnotetext{
um ensaio para irmos chegar, sem correr, aos destinos, que o futuro nos prepara. Se é uma utopia querer de repente chegar a um sistema perfeito de liberdade, também é utopia querer ficar estacionário; e se o Brasil já não está capaz de um Governo federal, também não é possivel ser governado como tem sido até o presente.

Logo, continuou o Senador,

é necessário marchar progressivamente no sistema, isto é não atacar a unidade do Império, não é derrubar a Monarquia, pelo contrário, é fortificar, mais uma e outra coisa, pondo as instituições em harmonia com as necessidades e sentimentos dos povos. ${ }^{16}$
}

0 trecho demonstra elementos centrais da linguagem política do momento: 1) a adequação das mudanças políticas às "necessidades públicas", tópico que aparece em diversos momentos através de outras expressões como respeito às "circunstâncias", ou "experiências" e "fatos"; 2) a necessidade de não ir rápido demais com as mudanças, $r$ mas ao mesmo tempo não se bloquear completamente qualquer mudança. Em termos mais dire- 
tos, o problema com que se defrontavam os homens públicos era o de fazer mudanças de forma cautelosa, respeitando as instituições monárquicas, a ordem e a unidade do Império, mas adicionando elementos de liberdade no ritmo que o estado atual da sociedade exigia.

0 argumento nos dá a oportunidade de ensaiar uma hipótese de trabalho. Ao longo dos anos 1830, o campo de experiências interno que faltava aos constituintes e deputados da primeira década pós Independência foi sendo construído a partir das avaliações dos processos políticos desencadeados pela Abdicação, e agravado pela experiência de descentralização política iniciada com a reforma do Código de Processo Criminal em 1832 e o Ato Adicional de 1834. A partir das reformas descentralizadoras, as autoridades eletivas locais ganharam maior autonomia frente ao poder central. Nos debates políticos pela via parlamentar e pela imprensa escrita, a avaliação de que o Império estava sendo levado à desordem, com graves riscos à unidade territorial, se tornaria assunto contumaz nos debates dos deputados e senadores de amplos setores. As críticas às autoridades eletivas locais se tornaram frequentes, especialmente após os anos conturbados de 1835 a 1837, período no qual ocorreram as maiores rebeliões provinciais, dando ensejo ao movimento conhecido como Regresso Conservador, consubstanciado com a criação do Partido Conservador.

Tal transformação político-ideológico foi imediatamente também uma mudança nas percepções e representações do tempo. Ao longo dos anos de 1830, vemos um acento cada vez mais evidente nos temas da "circunstâncias", do "estado", das "necessidades" do país, que deveriam ser diagnosticadas e levadas em conta na projeção da ação política. As referências clássicas, embora não tenham desaparecido, foram subsumidas pelo esforço de avaliação do que era considerado a "experiência atual" por que passava a jovem nação, o que configurava uma espécie de embrião de sociologia política que perduraria na linguagem política nacional. Os impasses da experiência "democrática" dos anos 1830, como era visto na época, criaram um novo "espaço de experiências" nacional, com densidade o suficiente, na visão dos contemporâneos, para embasar as perspectivas futuras.

A experiência política iniciada após a Abdicação de D. Pedro I foi lida por muitos contemporâneos como uma verdadeira revolução. Embora o fato não tenha sido realizado com derramamento de sangue nem com a violência que acompanhou a maior parte dos processos revolucionários modernos, ganhou a conotação de um verdadeiro recomeço. É claro que homens particularmente fiéis à monarquia, como o então senador pela província de Alagoas, o Marquês de Barbacena, se esforçaram por depurar o fato deste caráter revolucionário, ressaltando a todo o momento a continuidade com o regime monárquico e a não quebra das bases sociais e políticas pactuadas desde a Independência. Para o Marquês, o cuidado com as palavras era central, e o termo revolução não era apropriado para designar o momento que deu origem ao governo regencial: faz a revolução; porém quando, como no Rio de Janeiro, recorre aos Juizes de Paz e os manda ao Palácio pedir ao Soberano a demissão do Ministério (...) faz uma súplica. Nestas circunstâncias, preferido o Soberano antes abdicar, do que mudar de Ministério, onde diremos que esteja a revolução? Poder-se-á dizer: houve excesso, devia o povo fazer a súplica de outro modo - mas todavia não é isso que se chama revolução. (...) não confundamos, pois representação enérgica com revolução, nem abdicação voluntária com expulsão. Em negócio desta magnitude toda a circunspecção, toda a exatidão nos termos é indispensável. ${ }^{17}$ 
ARENDT, Hannah. Da Revolução. São Paulo: Ática, 1990.

19

KOSELLECK, Reinhart. Critérios históricos do conceito moderno de revolução. In: Futuro Passado. Contribuição à Semântica dos Tempos Históricos. Rio de Janeiro: Contraponto : Ed. PUC-Rio, 2006.
Seja como for, para muitos, acredito, a experiência histórica que se iniciou teve o tom de um "novo começo" ${ }^{18}$ de libertação, de onde se desprenderam possibilidades políticas novas e inesperadas. Era uma experiência percebida como inovação, o que exigia dos agentes políticos o esforço para conhecê-la e dominar sua marcha. Como ressaltou Koselleck, a revolução moderna se distingue das demais formas de movimento social e político comuns em outros períodos da história por fazer de si não mais um retorno a um momento ou regime do passado, mas um espaço novo, autorreferenciado e autolegitimado, um espaço de experiência novo, em que as diferentes fases e circunstâncias do processo revolucionário se tornam 0 lugar de onde se pode extrair lições para a caminhada rumo ao futuro que se estava abrindo. ${ }^{19}$

Entretanto, esse novo espaço trazia desafios específicos. Se as expectativas da libertação do regime considerado opressor e despótico podiam ser formuladas com amplitude e relativa radicalidade, em especial pelos grupos políticos que lideraram o 7 de Abril, a experiência real da liberdade então posta em jogo após a Abdicação exigiu cada vez mais uma atitude de prevenção dos agentes envolvidos. Como nos lembrou Hannah Arendt, a liberdade negativa e a liberdade positiva, isto é, a experiência de cunho negativo da "libertação" em relação ao opressor, mas também a experiência da liberdade como participação na vida da pólis recém-criada, fazem parte da experiência moderna da revolução, embora, os agentes envolvidos não tenham a noção clara da diferença os dois aspectos da liberdade até que a revolução ocorra e instaure de fato uma nova realidade.

Tal experiência de ser livre trouxe mais uma vez o problema da determinação das regras e limites institucionais da participação. No Brasil, tal experiência exigiu das elites políticas cuidado redobrado na execução das reformas descentralizadoras do poder político-administrativo, elemento que foi se ampliando ao longo da década no ritmo do acirramento das guerras civis nas províncias do Império. É preciso não perder de vista que as primeiras experiências nacionais de liberdade (a Independência, a Abdicação e a formação do regime regencial) foram realizadas após todo o processo de revisão crítica da Revolução Francesa pelo liberalismo da Restauração, e depois pelo Liberalismo Doutrinário. Deram-se no contexto europeu da Restauração pós-napoleônica e da formação das monarquias constitucionais liberais e moderadas dos anos de 1830. Logo, o tópico dos limites da liberdade e do apelo às experiências e circunstâncias contra o que era visto como utópicas e abstratas teorias eram já parte intima da sensibilidade política de então. 0 pensamento político europeu, especialmente o Francês, já havia chamado a atenção para as novas responsabilidades e tarefas da política moderna, que a afastavam da simples afirmação revolucionária do princípio da liberdade, colocando a ação política na dependência de um novo tipo de diagnóstico do "real" estado das nações.

Koselleck apontou muito bem a especificidade do tempo histórico nesta primeira metade do século XIX na fórmula que, creio, resume bem 0 que se passava na experiência política brasileira:

\footnotetext{
Quanto menor o conteúdo da experiência, tanto maior a expectativa que se extrai dele. Quanto menor a experiência, tanto maior a expectativa - eis uma fórmula para a estrutura temporal da modernidade, conceitualizada pelo 'progresso'. Isso foi plausivel enquanto as experiências anteriores não eram suficientes para fundamentar as expectativas geradas por um mundo que se transforma tecnicamente. Mas depois de haverem nascido de uma revolução, quando os projetos
} 
Idem. "Espaço de Experiência" e "Horizonte de Expectativa". Duas categorias Históricas. In: . Futuro Passado. Op. Cit., p.273

21

ANAIS DO SENADO IMPERIAL. Op. Cit., 30 de maio de 1832.

22

LYNCH, Christian Edward Cyril. Modulando o tempo histórico. Bernardo Pereira de Vasconcelos e o conceito de regresso na virada conservadora brasileira (1838-1839). In: CICLO DE DEBATES DO NEHM, 2014, Mariana, Minas Gerais.

23

ANAIS DO SENADO IMPERIAL. Op. Cit., 28 de maio de 1832. políticos correspondentes se transformaram em realidade, as velhas expectativas se desgastam nas novas experiências (...) quanto maior a experiência, tanto mais cautelosa, mas também tanto mais aberta a expectativa. ${ }^{20}$

Esta "cautela" de que falou Koselleck se traduzia, na experiência do Brasil dos anos 1830, em uma tentativa não de frear as mudanças rumo a uma maior descentralização - como fica claro no discurso de José Martiniano de Alencar citado no início do artigo - mas de fazê-las seguir o passo necessário, tendo em vista as características do mundo social a que se destinavam. Como Koselleck assinalou, as expectativas de transformação se tornaram cautelosas, mas não deixaram de existir, ganhando até mesmo uma força futurista mais contundente, embora num ritmo mais vagaroso. As reformas foram vistas de modo geral como forma de acelerar as instruções e virtudes do povo, isto é, de acelerar o processo rumo à civilização do país. Embora lentas, as mudanças eram vistas como necessárias, o futuro almejado seria ainda grandioso, e os "melhoramentos" constantes não poderiam cessar. Como lembrou o Marquês de Barbacena,

\footnotetext{
a instrução e virtude de um povo não precede as boas instituições; são sempre consequência delas; é por isso que é nos seu melhoramento e reforma que principalmente se deve ocupar os Legisladores (...). É pois das instituições que depende o caráter nacional, o seu melhoramento deve ser constante e progressivo, e tanto mais necessário quanto maior a ignorância e imoralidade. ${ }^{21}$
}

Este sentimento de que era necessário "cautela", mas com manutenção de um ritmo constante de mudanças institucionais e societárias, era dominante no Senado. Precisamos ter em mente, como salienta Christian Lynch ${ }^{22}$, que diversamente da Europa, em que uma parte dos políticos mais conservadores tinha o Antigo Regime ou mesmo a medievalidade para buscar elementos sustentadores de suas posições, em países novos como 0 Brasil, recém-saídos do estado colonial, qualquer reivindicação radical da autoridade do passado seria difícil de ser sustentada e facilmente refutável, uma vez que este seria identificado ao despotismo colonial, momento em que o país nem mesmo existia enquanto tal. Era como se a consciência política brasileira estivesse condenada ao futuro modernizante. Portanto, para usar as já citadas palavras de koselleck, embora com prudência e cautela, as expectativas permaneciam inabalavelmente orientadas ao futuro, mesmo no campo chamado conservador do espectro político dos anos de 1830.

Argumentos semelhantes aos de José Martiniano de Alencar foram ventilados pela maioria dos Senadores durante a continuidade da discussão do projeto em 1832. Por exemplo, o Senador pela província de Pernambuco, Almeida e Albuquerque, chamou a atenção para a diferença dos "destinos" do Brasil em relação aos "Lacedemônios", que necessitavam, para manter sua ferocidade de caráter, de leis muito duras e restritivas quando o Brasil, em comparação, teria a possibilidade de conceder maior liberdade aos seus cidadãos. Portanto, dizia, devemos "marchar a par dos progressos das luzes e da civilização: e se tudo muda no homem, e em roda dele, como deixarão de mudar as instituições?". As "leis administrativas", prossegue o Senador, devem mudar sim, mas com "processos pacificos e regulares", de acordo com os nossos "costumes e necessidades", de forma regulada pela "experiência que não vem senão depois de largo tempo". Albuquerque via como natural a necessidade de reformas na Constituição, mas sempre ressaltando a maneira "cautelosa com que devemos proceder nesta matéria". ${ }^{23}$ 
ANAIS DO SENADO IMPERIAL Op. Cit. 24 de maio de 1832. p.344.

25

ANAIS DA CÂMARA DOS DEPUTADOS, 31 de agosto de 1832. Disponivel em: <http:// www2.camara.leg.br/documentos-e-pesquisa/ publicacoes/publicacoes-e-estudos>.

26

Os EUA, "não só resolveu um problema de grande dificuldade em política, mas que vive feliz com a forma de governo definitivamente estabelecido no momento critico de sua independência. Mas nego, e ninguém me convencera em presença dos fatos que aquele povo antes da revolução de 1776 fazia um corpo de nação composto e unido, como o Brasil". ANAIS DA CÂMARA DOS DEPUTADOS. Op. Cit., 31 de agosto de 1832 .
Claro que havia senadores que se postavam como bastante temerários quanto às transformações possiveis que adviriam das reformas constitucionais. Por exemplo, João Evangelista, senador pela província de Minas Gerais, num momento em que se discutia a substituição de José Bonifácio de Andrada e Silva do cargo de tutor do infante D. Pedro II, questionava a conveniência de se fazer tal mudança naquele momento:

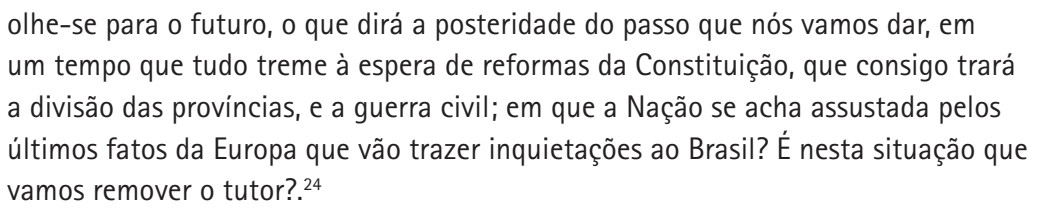
um tempo que tudo treme à espera de reformas da Constituição, que consigo trará a divisão das províncias, e a guerra civil; em que a Nação se acha assustada pelos últimos fatos da Europa que vão trazer inquietações ao Brasil? É nesta situação que vamos remover o tutor? ${ }^{24}$

Entretanto, este "tempo em que tudo treme" dos anos de 1830, caracterizado pela instabilidade política e social, embora tenha causado temor, não fez com que a maioria dos senadores ficasse contrária a qualquer mudança. Estas foram aceitas, porém como o acautelamento quanto ao seu ritmo e profundidade.

Esta postura não se limitou ao Senado. A discussão que deu origem ao Ato se iniciou em 1831 na Câmara dos Deputados e foi marcada desde o início pelo esforço da ala mais moderada de pôr freio à exacerbação do princípio federalista, embora a necessidade do aperfeiçoamento da Constituição fosse consenso. A proposta da comissão encarregada de redigir o texto era, como se sabe, bastante ousada, sugerindo a supressão do poder moderador e a adoção de um modelo de "monarquia federativa". Na seção de 31 de agosto de 1832, o deputado pela província da Bahia, Francisco Jê Acaiaba de Montezuma, defendeu que o Brasil necessitava de uma reforma parcial e não de uma refundação do pacto social. Segundo ele, os poderes das Assembleias Legislativas já haviam sido definidos pela Constituição, com o apoio da opinião nacional. Mudanças radicais seriam fundadas em teorias abstratas, que deveriam ser evitadas em nome da "utilidade e dos fatos":

\footnotetext{
Hoje prefere-se mais o positivo aos princípios teóricos e abstratos. Os povos já se não deixam arrastar por palavras vãs; querem que a política assente sobre fatos, e mais que tudo sobre a política e geral utilidade. Mas é por ser respeitador da soberania nacional, que ou não quero arrogar-me poderes que ela não me delegou. ${ }^{25}$
}

Era necessário, para homens como Montezuma, reconfigurar o debate, abandonando o mote das doutrinas, princípios e teorias rumo ao campo conceitual considerado mais moderno e sensato, onde conceitos como de circunstâncias, experiências, realidade, fatos e utilidade dominavam o novo léxico. Para isso, era necessário, por exemplo, deixar de importar modelos políticos e administrativos estrangeiros. A liberdade federativa de que gozavam os Estados Unidos era apropriada para aquela realidade, não podendo servir de princípio em política. As colônias inglesas na América sempre tiveram alto grau de autonomia, argumentou Montezuma, o que era diferente da realidade brasileira atual, em que uma monarquia the dava coesão nacional num grau muito maior do que na América inglesa no momento da Independência. ${ }^{26}$

A mesma problemática pode ser vista dois anos depois no famoso discurso do deputado mineiro Bernardo Pereira de Vasconcelos, exemplar no que diz respeito à pretensão de acomodar as os projetos de organização política e administrativa aos fatos, condições e circunstâncias nacionais. Vascon- 
27

Discurso na Câmara dos Deputados. Sessão de $1^{\circ}$ de Julho de 1834. In: VASCONCELOS, Bernardo Pereira de. Bernardo Pereira de Vasconcelos. CARVALHO, José Murilo de (org). São Paulo: Ed. 34, 1999. p.223.

28

ANAIS DA CÂMARA DOS DEPUTADOS DO IMPÉRIO. Op. Cit., 31 de agosto de 1832.

29

ANAIS DO SENADO IMPERIAL. Op. Cit., 7 de julho de 1835 . celos postou-se contrário a elementos do projeto que, a seu ver, tornariam as províncias demasiado soberanas. Segundo Vasconcelos, o Brasil não estaria pronto para o federalismo, ao contrário dos Estados Unidos, em que:

tudo estava harmonizado para estabelecer o melhor sistema federativo possivel; no Brasil não existe esta harmonia: nós temos o principio hereditário; pelo hábito, costumes e estado da civilização não podemos adotar semelhante ideia; temos uma câmara vitalícia, que por muito tempo tem saboreado o gosto de um poder grande $(. . .)^{27}$

Essa virada em direção aos fatos recentes da experiência brasileira, e a rejeição ao que eram consideradas vãs teorias, ou argumentos baseados em experiências estranhas à realidade nacional, começou a tornar-se muito frequente. Tratava-se, claro, também de uma tópica chave do liberalismo oitocentista, presente nas obras políticas de Benjamin Constant, Guizot e Tocqueville, muito influentes entre as elites daquele momento. A ascensão deste tema no debate brasileiro, que não era uma novidade, evidentemente, tendo estado presente já no início dos anos 1820, se devia, entretanto, não apenas a uma influência intelectual de teorias europeias, mas ao imperativo de diagnosticar fenômenos cuja magnitude impelia a reorientações na atividade de projeção política. Assim como o movimento restaurador europeu elegeu a Revolução Francesa e, sobretudo, o período do Terror, como o grande campo de experiências políticas orientadoras, no Brasil a experiência de descentralização política dos anos 1830, com suas revoltas, motins e guerras civis, teve o mesmo papel.

0 conceito de "fato" foi muito utilizado nestes discursos. A observância dos "fatos" atuais aparecia com muito mais vigor na argumentação política destes anos de 1830, quando comparados com os da década anterior. Francisco de Montezuma, em debate a respeito da Criação do Código de Processo em 1832, lembrava que, na atualidade, "os povos querem que a política assente sobre fatos, e mais que tudo sobre a política e geral utilidade" ${ }^{\prime 2}$. Era preciso seguir uma tendência geral do povo que naquele momento já extraía suas opiniões e "as suas ideias no que se via", deixando de lado "raciocínios velhos", como argumentou mais tarde em 1835 o senador pela província da Bahia, Marquês de Caravellas. ${ }^{29}$

Dois anos depois, o aparecimento destas concepções se amplificou. Por exemplo, no debate a respeito do número de deputados que deveriam compor as assembleias provinciais. A comissão encarregada de redigir o projeto definiu números previamente fixados: 36 membros nas Províncias de Pernambuco, Bahia, Rio de Janeiro, Minas e São Paulo, 28 no Pará, Maranhão, Ceará, Paraíba, Alagoas e Rio Grande do Sul, e 20 em todas as outras, sendo que este número poderia ser alterado por lei geral, isto é, pela Assembleia Nacional. Uma emenda procurou dar às Assembleias Provinciais o direito de definir tais números, o que seria uma ampla concessão à descentralização. Na discussão que se seguiu, muitos argumentos levantaram-se em contrário. 0 deputado por São Paulo, Francisco de Paula Souza e Melo, argumentou que esta medida feriria a uniformidade das províncias e a unidade nacional. Mais uma vez, a comparação com a situação norte-americana é colocada. Enquanto a população dos Estados Unidos era composta por estados diversos, tinha leis diversas e não havia um centro forte, optou-se pela federação como forma de unidade contra o perigo da dispersão. No Brasil a realidade era outra: as províncias não eram estados separados, mas compunham um mesmo Império, e o que se procurava com 
ANAIS DA CÂMARA DOS DEPUTADOS. Op. Cit., 25 de junho de 1834, p.173.

31

"Muitas vezes a vida de um povo esta no que 0 legislador julga uma excrescência defeituosa, (...) Se o legislador depois conhece pela experiência que e pela observação seu erro, há de insistir nele, porque já uma vez disse que aquele objeto era inútil e podia eliminar-se das instituições do país em perigo? Filósofos que viveram há poucos anos sustentaram que a história era o estudo mais desnecessário, sendo hoje a opinião contraria geralmente seguida". In: VASCONCELOS, Bernardo Pereira de. Bernardo Pereira de Vasconcelos. Organização e Introdução de José Murilo de Carvalho. São Paulo: Ed. 34, 1999. p.94.

32

ANAIS DO SENADO IMPERIAL. Op. Cit., livro 3 , 1840, p.67.

33

GAUCHET, Marcel. La Condicion Historica. Conversaciones com Francois Azouvi y Sylvain Piron. Madrid: Trotta, 2007. a reforma era apenas afrouxar um pouco os laços, sem ferir a uniformidade deste Império. 0 Brasil não estaria "a par dos povos mais avançados em civilização". Logo, segundo o deputado pela província do Piauí, Souza Martins, "nem todos os povos devem de chofre receber instituições para que não estavam preparados"30.

0 tópico da observação dos fatos, da experiência e do grau de civilização, pautou o movimento pelas reformas do chamado "regresso conservador" a partir de 1837. 0 movimento era justificado pela contingência da situação social e pelo momento civilizacional do povo. A história recente do Brasil havia mostrado para estes homens que as ideias abstratas de liberdade e progresso haviam levado à onda revolucionária e à anarquia. 0 legislador deveria, portanto, voltar os olhos para a vida do seu povo. ${ }^{31}$ São muitos os exemplos de discursos que poderíamos arrolar, mas um em especial parece ter dado a tônica do fenômeno ao qual queremos iluminar. Em 1840, nas vésperas da aprovação das reformas regressistas, Paulino José Soares de Souza esforçou-se por mostrar em discurso no Senado, como então Ministro da Justiça, que o progresso não podia transformar-se num ideal cego que não atentasse para a realidade da vida do povo e para a sua história. Era preciso mergulhar na história do país, nos fatos, circunstâncias e costumes nacionais. A "vida do povo" brasileiro foi identificada diretamente aos oito anos da experiência regencial:

\footnotetext{
Não é em fatos acontecidos em países estranhos, não é somente nas teorias dos jurisconsultos, que se devem estudar e procurar remédios. É nos fatos, é na experiência do próprio país para o qual se legisla. Ora, é nesses fatos, é nessa experiência das nossas coisas que a administração encontra mais fortes razões para conformar-se com o projeto em discussão e apoiá-lo, e para persuadir-se que a sua adoção é um dos maiores benefícios que se pode fazer ao País. Sinto ter de recordar ao Senado acontecimentos melancólicos, que todos deploramos (....). ${ }^{32}$
}

Embora não fosse uma perspectiva que expressasse todas as posições e projetos políticos de então, o discurso do famoso ministro da justiça demonstrou o aprofundamento da história como experiência coletiva das elites políticas na segunda década de existência do Brasil como nação independente. A experiência do mundo social coletivo ganhava maior espessura, tornando cada vez mais anacrônica a linguagem do Direito Natural e dos princípios atemporais que povoava a racionalidade ainda bastante próxima da llustração dos anos 1820, bem como a perspectiva tradicional da história como campo desconexo e plural de exemplos pedagógicos. Ainda que embrionariamente, a sociedade entendida como unidade complexa de experiências humanas no tempo, apontada por Marcel Gauchet ${ }^{33}$, como marca da História como experiência coletiva na modernidade, passaria a ser o foco central das análises e projeções políticas, uma tendência que se aprofundaria nas décadas posteriores. A projeção da ação política estaria deixando de ser baseada em princípios constantes para se abrir a uma experiência nacional densa e impositiva, cuja pujança parecia impor-se à razão política.

"Fatos", "experiências", "circunstâncias", "grau" ou "estado de civilização": através deste conceitos, mais ou menos elaborados na linguagem do momento, os senadores e deputados pretendiam abordar a realidade nacional da década de 1830. Mas que realidade era esta? De que fatos e circunstâncias se tratavam? Chama a atenção o fato de que pouco se aventava a crítica ao povo em termos raciais, culturais. Nota-se um ver- 
34

ANAIS DO SENADO IMPERIAL. Op. Cit., seção do dia 23 de maio de 1834

35

Ibidem, Senador Manoel Caetano de Almeida e Albuquerque, 28 de maio de 1832, p.144.

36

ANAIS DO SENADO IMPERIAL. Loc. Cit.

37

ANAIS DO SENADO IMPERIAL. Loc. Cit.

38

ANAIS DO SENADO IMPERIAL. Loc. Cit. Senador Manoel Caetano de Almeida e Albuquerque.

39

ANAIS DO SENADO IMPERIAL. LOC. Cit.

40

ANAIS DO SENADO IMPERIAL. Loc. Cit. dadeiro pudor em ofender o povo. As circunstâncias negativas não diziam respeito, na grande maioria das falas, a qualquer característica intrínseca ao povo-nação. Era preponderante a concepção de que o que caracterizavam essas tão propaladas "circunstâncias" era o que o senador cearense Rodrigues de Carvalho chamou de "comoções parciais, anômalas acéfalas, que ainda perturbam duas províncias do Império", ocasionadas pela "mesquinha pequenez desses bandos, ordinários em tempos de revolução, que com a capa de oposição ao novo regime se afana por aluir o edifício social e pela queda do governo a quem a mesma nação confiara seus destinos"34. As circunstâncias eram, para esses homens, sobretudo identificáveis à guerra civil, onde dominavam as paixões de partido e facções.

Ao contrário destes grupos dominados pelos seus mais vis sentimentos, o povo aparecia, ao contrário, como o guardião do "bom senso", aquele que apenas se envolvia nas rebeliões quando "conduzido de boa fé pelos "interessados de facções" ${ }^{3}$. Era comum a noção de que
A Massa geral" ainda não está de todo contaminada; os homens probos ligados aos seus verdadeiros interesses, apesar das pérfidas sugestões dos que os rodeiam, não aspiram senão gozar em paz os frutos do regime legal, eles reclamam a manutenção da ordem, sem a qual todos os direitos são comprometidos, eles serão o nosso escudo, para garantirmos a Constituição a essas mesma porção, que impelida somente por uma inclinação irresistivel da natureza humana, imprudente anela mudanças após de uma quimera. ${ }^{36}$

0 povo brasileiro seria historicamente, para o senador por Minas Gerais, Antônio Gonçalves Gomide, "o mais moralizado do mundo" (...) e peculiar pela "docilidade e temperança". Embora Ihe faltasse instrução, não Ihe faltava o "talento fino para conhecer a verdade; de critério para averiguá-la; e de índole para segui-la. (...). Para Gomide, o único defeito do povo brasileiro era o de "ser levemente crendeiro, tomando com boa fé insinuações e conselhos de algumas pessoas que lhe falam com dissimulação e hipocrisia, não tendo outro fim que fazer de nós Povo degraus para escadas de sua ambição e cobiça. ${ }^{37}$.

Este diagnóstico das circunstâncias e fatos recentes, além de indicar a necessidade de cautela e vagar nas reformas, sugeria a necessidade de fazer do poder de administrar e legislar do Estado algo superior, que deveria estar em um lugar afastado e acima destas mesmas realidades. Uma vez que as circunstâncias impediam que se conhecesse de fato a vontade nacional, já que a guerra predominava, se fortaleceu a concepção que punha o Estado e a política como campos morais neutros, capazes de agir sobre uma sociedade ainda incapaz de governar-se e participar da pólis. Como disse um senador pernambucano ${ }^{38}$, tão difícil se tornava "em tempos de partidos, na efervescência das paixões" "conseguir o conhecimento da verdadeira opinião pública", que era necessário agir pelo bem da nação, colocando-se o legislador num lugar acima do domínio das paixões "contra as opiniões corrompidas e desorganizadoras" 39 . É importante ter em mente a visão que se tinha da atividade política no momento. Mesmo para aqueles favoráveis de modo geral às reformas constitucionais, era fundamental que a "égide impenetrável da razão" imperasse sobre as "vozes de um povo alucinado e conduzido de boa fé pelos interessados de facções"40.

$\mathrm{Na}$ consciência deste momento, a política deveria ser o lugar moral despido do domínio das paixões dos partidos. Era preciso, portanto, garantir e promover a ordem contra os que são impelidos apenas "por uma 
Além de Marcel Gauchet e Pierre Rosanvallon, outra referência fundamental é Hanah Arendt que 0 homem, segundo Hannah Arendt, não tem uma "essência política", tal qual imaginou Aristóteles. Antes, a política é uma dimensão que surge como construção puramente humana que se estabelece na relação entre os homens diferentes e plurais. inclinação irresistivel da natureza humana"41. À natureza humana dominada pelas paixões, era preciso opor a prudência que apenas a experiência histórica recente nos assuntos políticos e sociais poderia fornecer. Embora fundamentalmente orientados para o futuro, os discursos do Senado favoráveis à reforma nunca perdiam de vista, portanto, a postura de prudência que se deveria adotar, tendo em vista as experiências e circunstâncias.

\section{Conclusões}

Este texto procurou demonstrar em primeiro lugar que o debate político direto realizado pela via parlamentar é um lugar para se entender o tempo histórico, uma vez que o âmbito das instituições políticas é, por excelência, um lugar da construção coletiva sobre o que se consideram numa dada época as experiências orientadoras da ação e o horizonte de expectativas de futuro. 0 "político" é o âmbito da vida em que se dá o trabalho de criação dos sentidos do que se considera o espaço do coletivo no seio da diferença e no conflito. ${ }^{42}$ As estratégias linguísticas desenvolvidas neste domínio são constituídas mediante a tensão entre o experimentado e 0 movimento de reconfiguração e projeção. É no interior desta articulação que se dá a construção constante do âmbito político pelos diversos pontos de vista e grupos de interesses políticos. Sendo assim, acredito que o político é uma das instâncias fundamentais da figuração coletiva tempo no espaço público.

Acredito ainda que a década de 1830 apresenta mudanças consideráveis no campo da linguagem política em uso pelos maiores expoentes políticos reunidos nos órgãos de representação da Corte do Rio de Janeiro. A abdicação de D. Pedro I, vista como um momento de refundação do pacto político por muitos setores, a formação do governo regencial, em que os anseios reformistas liberais puderam se expressar com mais liberdade, $e_{\text {, }}$ sobretudo, todos os conflitos político-sociais que se fizeram presentes nas diversas províncias, foram tomados como um novo espaço de experiências com capacidade norteadora das decisões sobre o futuro.

As deliberações no âmbito político passaram a ser vistas como devedoras de diagnósticos racionais baseados nos "fatos", "circunstâncias", "estados", isto é, naquilo que se pode observar na realidade presente, mais do que em exemplos históricos antigos ou em princípios políticos abstratos e teóricos. A interpretação sobre as primeiras experiências de maior liberdade política após a Independência, que possibilitaram o debate e a realização das reformas constitucionais de cunho federalista, somada ao verdadeiro trauma que representaram os inúmeros motins, rebeliões e guerras civis, se condensou em uma espécie de novo espaço de experiências genuinamente nacional e contemporâneo de cunho pedagógico para a política. Tal espaço causou um sentimento de cautela e vigilância na caminhada histórica rumo ao futuro, evitando-se precipitações ou acelerações rumo a reformas que estivessem em desacordo com as circunstâncias atuais. Tal cuidado não significava de modo algum um esforço absolutamente contrário a mudanças, muito menos uma postura de reação aristocrática ou retorno ao passado, uma vez que havia entre a maior parte destes deputados e senadores, mesmo aqueles mais conservadores, desde os primórdios da Regência, a expectativa de certa modernização das instituições e do povonação brasileiro. Era difícil sustentar uma postura unicamente reacionária, ao menos neste campo do debate político parlamentar sobre a reforma da constituição dos anos 1830, uma vez que, como demonstrou Christian 
Lynch, a história da nação era recente e o passado longínquo que se poderia reivindicar era o passado colonial. Isto não impedia, entretanto, que a principal herança dessa fase anterior, a dinastia dos Bragança, continuasse a ser defendida como parte constitutiva da nação política brasileira, embora o Estado Monárquico Constitucional e representativo fundado em 1822 fosse visto em geral, nos anos 1830, como um ato fundacional criador, e não como uma mera continuidade.

Circunstância e fato eram importantes conceitos ao mesmo tempo históricos e políticos no século XIX brasileiro, ao lado do conceito de progresso, normalmente tido como central na consciência histórica oitocentista. 0 conceito aparentemente tem um significado mais ligado à sincronia, à atualidade e à espacialidade, aludindo, portanto, a um estado momentâneo em determinado tempo e lugar que se podia "ver" e experimentar diretamente. Já o conceito de civilização, muito pouco desenvolvido em termos da explicitação de seu conteúdo na linguagem nos anos de 1830 no Brasil, pode ser visto, grosso modo, como um processo ou marcha diacrônica e universal, portanto, de caráter muito mais temporal. Muitas vezes, entretanto, os dois conceitos aparecem juntos nos argumentos políticos, de forma que a circunstância é vista como uma espécie de retrato instantâneo de um momento do processo civilizacional. Outras vezes, ainda, a ideia de civilização enquanto um "estado" e não como um processo propriamente, ainda é bastante frequente. Acredito que a centralidade dada a estes conceitos nestes anos se deve à necessidade urgente da racionalidade política de então de harmonizar mudança progressiva, utopia e otimismo, ao que consideravam os constrangimentos a este movimento que deveriam ser levados em conta. 0 desafio da época era acomodar mudança e estabilidade, experiência e expectativa.

É claro que este movimento não se restringiu à realidade brasileira, sendo, por exemplo, percebido, como vimos, por Koselleck, no caso alemão. Marcel Gauchet também nos indicou que a historicidade moderna não surge apenas do otimismo revolucionário das luzes, mas se desenvolve no século XIX através de uma crítica a este otimismo. Como nos diz este autor, a ideia de história surge precisamente na Alemanha como reflexão crítica sobre este modelo de ação histórica que foi a Revolução Francesa, e da necessidade de encontrar uma maneira de "assumir algo do projeto revolucionário recusando sua execução"43.

0 que talvez possa se configurar como uma diferença em relação ao caso brasileiro que analisamos, pode ser indicado quando Gauchet afirma que a consciência histórica oitocentista se caracteriza por assumir que "somos feitos de devir, que somos os herdeiros dos que nos precederam e seus modestos continuadores"44. Embora esta fórmula não seja de todo incongruente com o conjunto de argumentos que analisamos neste artigo, a ideia da continuidade com uma herança ou tradição, como elemento que pôs freio aos excessos de expectativas, pode ser matizada entre nós, uma vez que, ao menos, grande parte dessa herança não poderia ser reivindicada em um país novo e recém-saído da condição colonial. 